\title{
Disruption of adhC reveals a large duplication in the Mycobacterium smegmatis mc $^{2} 155$ genome
}

\author{
Alexandra Galamba, ${ }^{1}$ Karine Soetaert, ${ }^{1}$ Xiao-Ming Wang, ${ }^{1}$ \\ Jacqueline De Bruyn, ${ }^{1}$ Paul Jacobs ${ }^{2}$ and Jean Content ${ }^{1}$
}

1 Institut Pasteur de Bruxelles, rue Engeland 642 , B-1180 Brussels, Belgium

2 Université Libre de Bruxelles, Unité de Vectorologie et Oncologie Expérimentale, Hopital Erasme, Route de Lennik 808, B-1070 Brussels, Belgium

\author{
Author for correspondence: Jean Content. Tel: +32 2 3733416. Fax: +32 23733291. \\ e-mail: jcontent@pasteur.be
}

\begin{abstract}
Disruption of the adhC gene of Mycobacterium smegmatis $\mathbf{m c}^{2} 155$, by standard gene replacement methods, revealed that there are two copies of this gene within a large duplication of the $M$. smegmatis $\mathbf{m c}^{2} 155$ genome. M. smegmatis AdhC $^{+-}$and $M$. smegmatis AdhC ${ }^{-1-}$ mutants were obtained when one or two adhC copies, respectively, were disrupted by homologous recombination. Southern blot analysis of Dral restriction digests of the DNA from these mutants and from wild-type $M$. smegmatis $\mathrm{mc}^{2} 155$, resolved by PFGE, showed that the duplication size may be at least $\sim 250 \mathrm{~kb}$. The single and double knockout mutants were characterized and compared with the $M$. smegmatis wild-type. A growth disadvantage and a different morphology were associated with the loss of expression of one or both of the adhC copies, but both mutants were still acid-fast. Findings in this study indicate that the process of chromosomal duplication in $\boldsymbol{M}$. smegmatis is ongoing and remains a potent source of genome dynamics. Hence, the $M$. smegmatis $\mathbf{~ m c}^{2} 155$ genome might be larger than previously thought.
\end{abstract}

Keywords: homologous recombination, genomic duplication, merodiploidy, alcohol dehydrogenase C

\section{INTRODUCTION}

Tuberculosis remains a major world health problem and is responsible for approximately 2 million deaths each year (Dye et al., 1999). Although this infection can be treated effectively with multidrug therapy, incomplete treatment has led to the development of drug-resistant strains leading to the urgent need for specific targets for new anti-microbial agents. Since the cell wall is an attractive target for antibiotic development, considerable efforts have been focused on discovering the metabolic steps that are essential for biosynthesis of mycobacterial cell-wall components (Baulard et al., 1999; Besra et al., 1997; Lee et al., 1996; Mikusova et al., 1996).

Alcohol dehydrogenase C (ADHC) has been suggested to be a potential target for the development of new

Abbreviations: $A D H C$, alcohol dehydrogenase C; BCG-ADHC, M. bovis BCG ADHC; DCO, double cross-over; Ms-ADHC, M. smegmatis $\mathrm{mc}^{2} 155$ ADHC; SCO, single cross-over. antibiotics. This protein, initially purified and biochemically characterized from Mycobacterium bovis BCG, was suggested to contribute to the hydrophobic content of the mycobacterial envelope through its involvement in the biosynthesis of the free lipids required for envelope formation (De Bruyn et al., 1981a, b; Wilkin et al., 1999). The M. bovis BCG ADHC (BCG$\mathrm{ADHC}$ ) gene was cloned and found to be identical to the adhC gene from M. tuberculosis (Stelandre et al., 1992; Wilkin et al., 1999). BCG-ADHC is a dimeric zinc, NADP-dependent enzyme belonging to the long-chain alcohol/polyol dehydrogenase family, class C. To test the hypothesis that ADHC is essential in mycobacteiral envelope formation we undertook experiments to knock out the $a d h C$ gene and examine the effects of this mutation.

To avoid the difficulty of generating mutants by homologous recombination in slow-growing mycobacterial strains (McFadden, 1996), and to speed up the clarification of the physiological role of mycobacterial ADHCs, we first looked for such an enzyme in a fastgrowing and non-pathogenic mycobacterial strain. We 
have previously reported the identification of $M$. smegmatis $\mathrm{mc}^{2} 155$ ADHC (Ms-ADHC; Galamba et al., 2001), which shares $78 \%$ identity with BCG-ADHC and M. tuberculosis ADHC. The Ms-ADHC gene was cloned and sequenced, and the protein was purified, partially characterized and compared with BCGADHC. The two enzymes were found to be similar and functioned as aldehyde reductases in vitro, processing alcohols far less efficiently than aliphatic and aromatic aldehydes. It was also found that Ms-ADHC shares a strong degree of amino acid sequence similarity with the ADHCs of $M$. avium and M. paratuberculosis $(76 \%)$, and $M$. leprae $(75 \%)$. These results suggested that $M$. smegmatis $\mathrm{mc}^{2} 155$ could be used as a model to study the physiological role of the alcohol dehydrogenases in pathogenic mycobacteria. Thus, we used the cloned adbC gene to generate an ADHC knockout mutant of M. smegmatis $\mathrm{mc}^{2} 155$, by homologous recombination with a double cross-over (DCO) event. The resulting adhC-disrupted mutant should allow us to test the potential role of ADHCs in the mycobacterial cell envelope and to evaluate their in vivo significance as a target for anti-tuberculosis drugs.

In this paper we describe how the experiments undertaken to disrupt the $a d b C$ chromosomal allele (with a kanamycin-resistance gene) uncovered a large duplication in the M. smegmatis $\mathrm{mc}^{2} 155$ genome. In addition, the $\mathrm{AdhC}^{+/-}$and $\mathrm{AdhC}^{-1-}$ mutants were characterized and compared to the M. smegmatis wild-type with respect to growth and the utilization of some aldehydes in vitro.

\section{METHODS}

Bacterial strains and plasmids. The bacterial strains and plasmids used in this study are detailed in Table 1. Escherichia coli DH5 $\alpha$ was cultured on Luria-Bertani (LB; Sambrook et al., 1989) agar or in LB broth. For in vitro growth comparison studies the $M$. smegmatis strains were cultured in Middlebrook 7H9 broth or on Middlebrook 7H10 supplemented with $10 \%(\mathrm{v} / \mathrm{v})$ oleic acid-albumin complex for $36 \mathrm{~h}$ at $37^{\circ} \mathrm{C}$ Becton Dickinson.

Construction of the suicide delivery vector pAGA6KM. DNA manipulations were carried out according to standard techniques (Sambrook et al., 1989). The cloning strategy used for generating the suicide delivery vector is illustrated in Fig. 1. Primers G381, 5'-CGCGGATCCTCTCACAGGGTGTTCC3', and G382, 5'-CGCGGATCCGTTCCGGTGGTGATGCCGAA-3', (BamHI recognition sequences are underlined), were used to amplify a $1951 \mathrm{bp}$ fragment from pAGA5 (Galamba et al., 2001). The resulting PCR product was cloned into the BamHI site of pUC19 to generate pAGA6. A cassette containing the aphA-3 gene, which confers resistance to kanamycin (Menard et al., 1993), was used to disrupt the $a d h C$ gene. This cassette should not create polar mutations in genes downstream of $a d h C$, and was obtained by PCR from pUC18K, using the primers G379, 5'-GTGAATTCGAGCGGCCGCCCCGGGTG-3', and G380，5'-GACTCTAGAGGCGGCCGCGGTCATTAT-3', (NotI recognition sequences are underlined). The final delivery vector pAGA6KM contained the following selectable markers: a kanamycin-resistance gene; a hygromycin-resistance gene; and a gene that confers sucrose sensitivity. pAGA6KM also lacked a mycobacterial origin of replication (oriM); therefore it was a suicide plasmid unable to replicate in mycobacteria.

Electroporation of $\boldsymbol{M}$. smegmatis. $M$. smegmatis mc $^{2} 155$ was cultured in supplemented nutrient broth [SNB; nutrient broth plus $0.2 \%(\mathrm{v} / \mathrm{v})$ glycerol and $0.05 \%(\mathrm{w} / \mathrm{v})$ Tween 80$]$, in a shaking incubator at $37^{\circ} \mathrm{C}$ and 150 r.p.m. When $\mathrm{OD}_{600} 0.6$ was reached, cells were kept on ice for $2 \mathrm{~h}$ and then harvested by centrifugation $\left(11000 \mathrm{~g}, 10 \mathrm{~min}\right.$ at $\left.4^{\circ} \mathrm{C}\right)$. The cell pellet was then washed in cold $10 \%(\mathrm{w} / \mathrm{v})$ glycerol $(1 / 6$ vol. nutrient broth) and centrifuged $\left(4000 \mathrm{~g}, 10 \mathrm{~min}\right.$ at $\left.4{ }^{\circ} \mathrm{C}\right)$. The cell pellet was washed twice more with cold $10 \%$ (w/v) glycerol (1/15 and 1/30 vol. SNB, respectively), resuspended in $2 \mathrm{ml}$ $10 \%(\mathrm{w} / \mathrm{v})$ glycerol and stored at $-70{ }^{\circ} \mathrm{C}$ until needed. Plasmid DNA (100 ng) was pretreated with $100 \mathrm{~mJ}$ UV light $\mathrm{cm}^{-2}$ (Hinds et al., 1999) and used to electroporate $25 \mu \mathrm{l}$ of $M$. smegmatis competent cells in a $0.1 \mathrm{~cm}$ gap electroporation cuvette (Bio-Rad) at $1.66 \mathrm{kV}, 26 \mu \mathrm{F}$ and $200 \Omega$ using a Gene Pulser (Bio-Rad). Cells were immediately diluted with $1 \mathrm{ml}$ fresh $\mathrm{SNB}$ at room temperature, incubated in a shaking incubator for $3 \mathrm{~h}$ at $37^{\circ} \mathrm{C}$ and 150 r.p.m. and plated onto supplemented nutrient broth agar [SNBA; nutrient broth agar plus $0 \cdot 2 \%(\mathrm{v} / \mathrm{v})$ glycerol] containing $20 \mu \mathrm{g}$ kanamycin $\mathrm{ml}^{-1}$.

Analysis of the transformants. To distinguish between the single cross-over (SCO) and DCO homologous recombinants, the $\mathrm{Kan}^{\mathrm{R}}$ clones were plated out onto both sucrose/kanamycin SNBA $\left[10 \%(\mathrm{w} / \mathrm{v})\right.$ sucrose; $20 \mu \mathrm{g}$ kanamycin $\left.\mathrm{ml}^{-1}\right]$ and hygromycin SNBA (100 $\mu$ g hygromycin $\mathrm{ml}^{-1}$ ) plates. The $\mathrm{Kan}^{\mathrm{R}}$ $\mathrm{Hyg}^{\mathrm{S}} \mathrm{Suc}^{\mathrm{R}}$ DCOs were further analysed by Southern blotting and PCR. The DNA from the M. smegmatis mutants was extracted as previously described (Galamba et al., 2001). Southern blots of the DNA from each mutant were prepared after the DNA had been digested with BamHI, ApaI, Sfil or $B g l I I$. The restriction fragments were run out on $1 \%$ agarose gels and transferred to Hybond-N nylon membranes. Hybridizations were performed at $65^{\circ} \mathrm{C}$ as previously described (Galamba et al., 2001); the probes used for the hybridizations were Padh, Pkan, PsacB and Pdws (see Fig. 1 and Table 1). All of the probes were labelled by random priming with $\left[\alpha^{32} \mathrm{P}\right] \mathrm{dCTP}$ using a random priming kit (Amersham). PCR analysis was carried out either on extracted DNA or on individual colonies from the SCO and DCO recombinant strains. To carry out PCR from individual colonies, a colony from each transformant was resuspended in $1 \mathrm{ml}$ water, boiled for $25 \mathrm{~min}$ to liberate chromosomal DNA and cooled on ice for $10 \mathrm{~min}$. The liberated DNA was then used as a template for PCR amplification. PCR was carried out in $50 \mu \mathrm{l}$ reaction volumes containing $15 \mu \mathrm{l}$ of colony suspension and Taq DNA polymerase (Promega) under the following conditions : $1 \mathrm{~min}$ at $95^{\circ} \mathrm{C} ; 30$ cycles of $1 \mathrm{~min}$ at $95^{\circ} \mathrm{C}, 1 \mathrm{~min}$ at $60^{\circ} \mathrm{C}, 1.5 \mathrm{~min}$ at $72{ }^{\circ} \mathrm{C}$; and, a final $10 \mathrm{~min}$ extension period at $72^{\circ} \mathrm{C}$. Primers R59, $5^{\prime}$-TTCGTCGACTCCTGCCGAGA3', and G345, 5'-GTCGATGACGAAGCGGTAGCGCAC-3', were used for the PCR amplification. These primers were designed to amplify a $760 \mathrm{bp}$ fragment from the wild-type strain, and a $1500 \mathrm{bp}$ fragment from mutant strains that contained the aphA-3 cassette insertion.

PFGE and Southern blot hybridization of $\boldsymbol{M}$. smegmatis wildtype and mutant strains. Chromosomal DNA embedded in agarose plugs was obtained from $M$. smegmatis $\mathrm{mc}^{2} 155, M$. smegmatis $\mathrm{AdhC}^{+/-}$and M. smegmatis $\mathrm{AdhC}^{-/}$grown in $5 \mathrm{ml}$ modified Middlebrook $7 \mathrm{H} 9$ broth (Difco) containing $0.5 \mathrm{M}$ sucrose, $0.05 \%(\mathrm{w} / \mathrm{v})$ Tween $80,0.2 \%(\mathrm{w} / \mathrm{v})$ D-glucose and $10 \%$ (v/v) oleic acid-albumin complex (Beckman Dickson), for $24 \mathrm{~h}$ at $37^{\circ} \mathrm{C}$. Four hundred microlitres of a solution 
Table 1. Bacterial strains, plasmids and probes used in this study

\begin{tabular}{|c|c|c|}
\hline Strain/plasmid/probe & Relevant characteristics & Source/reference* \\
\hline \multicolumn{3}{|l|}{ Bacteria } \\
\hline E. coli $\mathrm{DH} 5 \alpha$ & Competent cells for cloning and plasmid propagation & Gibco-BRL \\
\hline M. smegmatis $\mathrm{mc}^{2} 155$ & Wild-type & Galamba et al. (2001) \\
\hline M. smegmatis $\mathrm{AdhC}^{+/-}$ & Single knockout mutant of $\mathrm{mc}^{2} 155$ & This study \\
\hline M. smegmatis $\mathrm{AdhC}^{-/-}$ & Double knockout mutant of $\mathrm{mc}^{2} 155$ & This study \\
\hline \multicolumn{3}{|l|}{ Plasmids } \\
\hline pUC19 & Vector & Gibco-BRL \\
\hline pAGA5 & $\begin{array}{l}\text { Contains a } 3.3 \mathrm{~kb} \text { fragment including } a d h C \text { from } M . \text { smegmatis } \\
\mathrm{mc}^{2} 155\end{array}$ & Galamba et al. (2001) \\
\hline pAGA6 & $\begin{array}{l}a m p, 1951 \mathrm{bp} \text { fragment containing coding sequence of } a d h C \text { with } \\
\text { an internal Not } \mathrm{I} \text { site, and flanking regions } 475 \mathrm{bp} \text { and } 429 \mathrm{bp} \\
\text { either side of } a d b C\end{array}$ & This study \\
\hline pUC18K & Contains an $a p h A-3$ cassette with an internal DraI site; Kan ${ }^{\mathrm{R}}$ & R. Menard; Menard et al. (1993) \\
\hline pAGA6K & $a m p, a d h C:: a p h A-3 ; \operatorname{Kan}^{\mathrm{R}}$ & This study \\
\hline pGOAL19 & byg, $\mathrm{P}_{A g 85^{-}}-\operatorname{lac} Z, \mathrm{P}_{h s p 60^{-}}-s a c B ; \mathrm{Hyg}^{\mathrm{R}} \mathrm{Suc}^{\mathrm{S}}$ & $\begin{array}{l}\text { T. Parish \& N. Stoker; Parish \& } \\
\text { Stoker }(2000)\end{array}$ \\
\hline pAGA6KM & 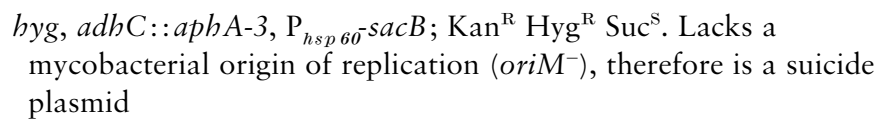 & This study \\
\hline \multicolumn{3}{|l|}{ Probes } \\
\hline Padh & $\begin{array}{l}\text { A } 1951 \text { bp fragment containing the adhC gene coding sequence } \\
\text { obtained by PCR amplification of pAGA5 with primers G381 and } \\
\text { G382 }\end{array}$ & This study \\
\hline Pkan & The $a p h A-3$ cassette & This study \\
\hline PsacB & $\begin{array}{l}\text { A } 2699 \text { bp fragment containing the } s a c B \text { gene obtained by the } \\
\text { digestion of pGOAL19 with PacI and Bam HI }\end{array}$ & This study \\
\hline Pdws & $\begin{array}{l}\text { A } 1230 \text { bp XmnI-KpnI fragment downstream of the ADHC ORF } \\
\text { obtained by digestion of pAGA5 }\end{array}$ & This study \\
\hline P600 & $\begin{array}{l}\text { A } 760 \text { bp fragment of the ADHC ORF downstream of where } \\
a d h C:: a p h A-3 \text { was inserted; obtained from pAGA5 }\end{array}$ & This study \\
\hline Pups & A 343 bp BamHI-EcoRV fragment upstream of the ADHC ORF & This study \\
\hline
\end{tabular}

*R. Menard, Unité de Pathogénie Microbienne Moléculaire, Institut Pasteur, Paris, France; T. Parish, Department of Medical Microbiology, St Bartholomew's and the Royal London School of Medicine and Dentistry, London, UK; N. Stoker, Department of Infectious and Tropical Diseases, London School of Hygiene and Tropical Medicine, London, UK.

containing $0 \cdot 2 \mathrm{M}$ glycine, $60 \mu \mathrm{g}$ D-cycloserine $\mathrm{ml}^{-1}, 20 \mathrm{mM}$ $\mathrm{LiCl}, 200 \mu \mathrm{g}$ lysozyme $\mathrm{ml}^{-1}$ and $5 \mathrm{mM}$ EDTA were then added to the cultures; the cultures were incubated for an additional $16 \mathrm{~h}$ and were then centrifuged at $1000 \mathrm{~g}$ for $20 \mathrm{~min}$ at $4^{\circ} \mathrm{C}$. The bacteria were recovered and resuspended in TS buffer (50 mM Tris, 0.5 M sucrose, $\mathrm{pH} \mathrm{7.6)} \mathrm{(1/50} \mathrm{culture} \mathrm{vol.).} \mathrm{The}$ cell suspensions were transferred to microcentrifuge tubes, immediately frozen in dry ice-methanol and then thawed on wet ice. The cell suspensions were then mixed with an equal volume of $1 \%$ low-melting-point agarose at $50{ }^{\circ} \mathrm{C}$ (Incert agarose; FMC Bioproducts) in TEN buffer $(50 \mathrm{mM}$ Tris, $250 \mathrm{mM}$ EDTA, $200 \mathrm{mM} \mathrm{NaCl}, \mathrm{pH} 7 \cdot 6$ ) and cast in plugs. The plugs were left to set for $20 \mathrm{~min}$, and were incubated overnight at $37^{\circ} \mathrm{C}$ in TE buffer $(10 \mathrm{mM}$ Tris, $1 \mathrm{mM}$ EDTA, pH 8) containing $1 \mathrm{mg}$ lysozyme $\mathrm{ml}^{-1}$ to lyse the cells. The plugs were then transferred to TE buffer containing 1\% SDS and $1 \mathrm{mg}$ proteinase $\mathrm{K} \mathrm{ml}^{-1}$ and incubated for $48 \mathrm{~h}, 55^{\circ} \mathrm{C}$. The plugs were transferred into fresh TE buffer and washed for 30 min, then transeferred to TE buffer containing 0.04 mg PMSF $\mathrm{ml}^{-1}$ incubated at $55^{\circ} \mathrm{C}$ for $30 \mathrm{~min}$. They were then washed three times, using only fresh TE buffer for each wash. The plugs were stored in $0.2 \mathrm{M}$ EDTA at $4{ }^{\circ} \mathrm{C}$. Before restriction digestion the plugs were washed twice in TE/Triton X-100 $(0 \cdot 1 \%)(\mathrm{v} / \mathrm{v})$ at $4{ }^{\circ} \mathrm{C}$ for $1 \mathrm{~h}$, and twice in restriction enzyme buffer/Triton X-100 (0.1\%) (v/v) for $1 \mathrm{~h}$ at room temperature; the plugs were then incubated overnight at $37^{\circ} \mathrm{C}$ in the presence of $\mathrm{DraI}(20 \mathrm{U})$. The restriction fragments were separated on a $1 \%$ agarose gel (Seakem GTG, FMC) in $0.5 \times$ TBE buffer (0.025 M Tris, $0.5 \mathrm{mM}$ EDTA and 0.025 M boric acid) containing $50 \mu \mathrm{M}$ thiourea, using a CHEF Mapper system (Bio-Rad) at $14{ }^{\circ} \mathrm{C}$ and $200 \mathrm{~V}$. For DraI-digested DNA from the wild-type and from clone 31, pulse times were ramped linearly from $1-40 \mathrm{~s}$ for $22 \mathrm{~h}$; pulse times for DraIdigested DNA from clone 18 were ramped 5-20 s for $20 \mathrm{~h}$. Bacteriophage $\lambda$ concatemers $(48.5 \mathrm{~kb})$ were used as DNA standards. Gels were stained with ethidium bromide, and examined and photographed under UV light on a transilluminator. The agarose gels were then treated with $0.25 \mathrm{M}$ $\mathrm{HCl}$ for $30 \mathrm{~min}$ before being treated following the standard Southern method and transferred by capillarity to a Hybond$\mathrm{N}$ nylon membrane. Southern blot hybridizations were performed using probes P600 and Pups (Table 1). P600 was 

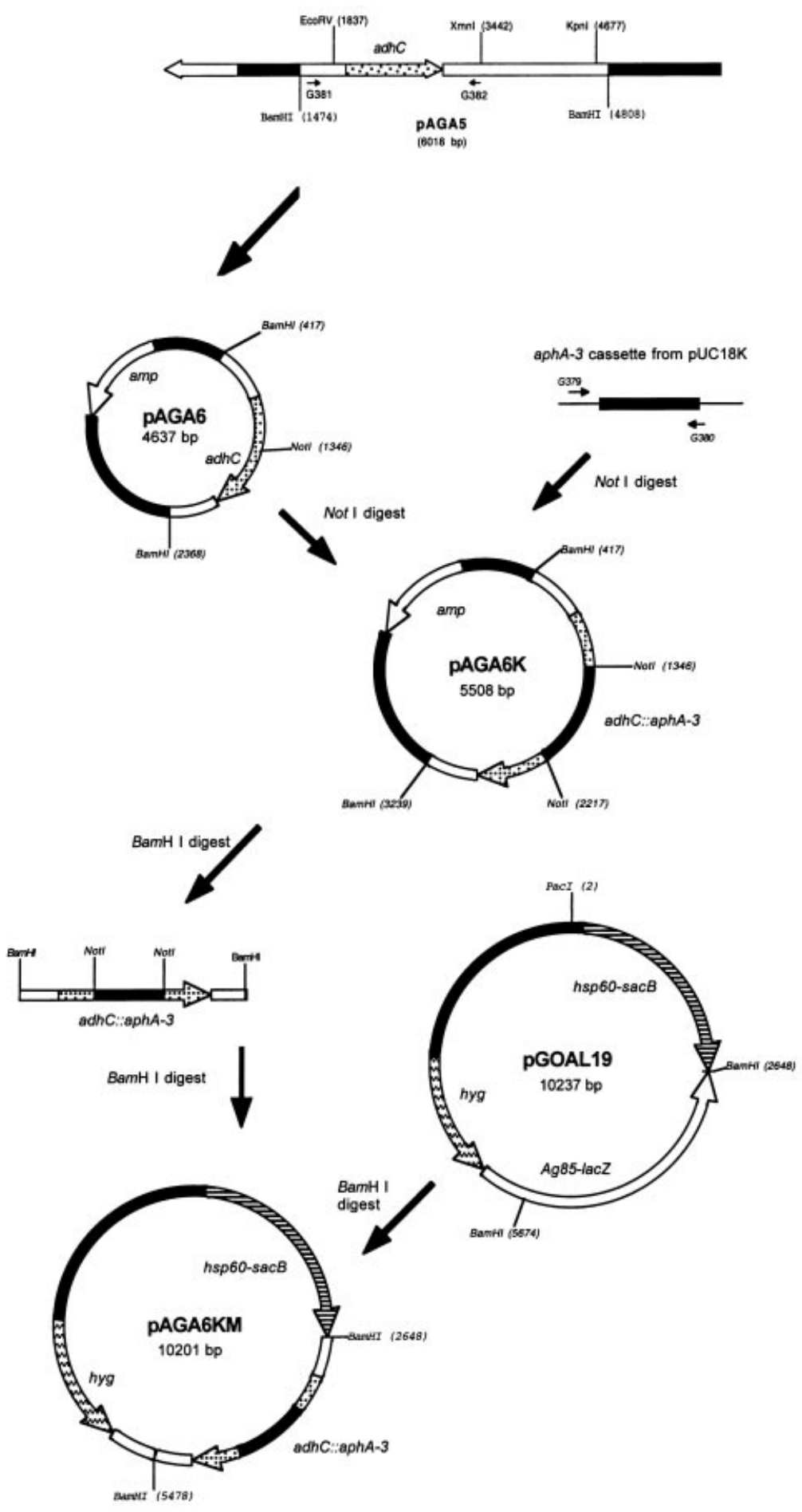

Fig. 1. Cloning strategy for generating the pAGA6KM suicide delivery vector. A $1951 \mathrm{bp}$ fragment, containing the $M$. smegmatis adhC gene, was obtained from pAGA5 by PCR and was cloned into the unique BamHI site of pUC19, to generate pAGA6. An 873 bp kanamycin cassette (aphA-3), obtained from pUC18K by PCR, was cloned into the unique Notl site of the adhC in pAGA6, to give pAGA6K. The suicide delivery vector pAGA6KM was generated by replacing the $3026 \mathrm{bp} B a m \mathrm{HI}$ lacZ fragment of pGOAL19 with the $2.8 \mathrm{~kb} \mathrm{BamHI}$ fragment of pAGA6K which contained the disrupted adhC (adhC::aphA-3). obtained by PCR amplification of pAGA5 with the primers G344, 5'-GCGCCGCTGTTGTGCGCGGGC-3', and G345.

SDS-PAGE and Western blot analysis. SDS-PAGE was carried out as described by Laemmli (1970) with $12 \%$ polyacrylamide gels on a Miniprotean II system (Bio-Rad). Proteins were transferred onto nitrocellulose filters with an LKB Multiphor II electrophoresis unit by semidry electroblotting. ADH was detected by incubation with a murine monoclonal antibody raised against the BCG-ADHC (4B5) (Stelandre et al., 1992) and developed with the Protoblot Western blot alkaline phosphatase system (Promega), according to the manufacturer's instructions.

Biochemical characterization of the adhC knockout mutants. M. smegmatis $\mathrm{mc}^{2} 155, \mathrm{AdhC}^{+/-}$and $\mathrm{AdhC}^{-/-}$mutants were grown on Sauton medium as surface pellicles for $3 \mathrm{~d}$ at $37^{\circ} \mathrm{C}$. The pellicles were recovered by filtration, sonicated with a 
probe tip sonicator (Vibra Cell) at $50 \%$ duty cycle for $10 \mathrm{~min}$ and then centrifuged $(11000 \mathrm{~g}, 15 \mathrm{~min})$. The protein concentration in the cell lysates was determined by the Coomassie brillant blue method (Spector, 1978) with BSA as the standard. $\mathrm{ADH}$ activity was assayed by monitoring the oxidation of NADPH by using a spectrophotometer (DU640B; Beckman Coulter) at $A_{340}\left(A_{366}\right.$ for cinnamaldehyde). This assay was carried out at room temperature in a $1 \mathrm{ml}$ reaction mixture $\left[\left(0.02 \mathrm{M} \mathrm{KH}_{2} \mathrm{PO}_{4} / \mathrm{Na}_{2} \mathrm{HPO}_{4}\right.\right.$ buffer, $\mathrm{pH} 7 \cdot 3 ; 0.25 \mathrm{mM}$ $\mathrm{NADPH} ; 25 \mu \mathrm{g}$ total protein) plus the aldehyde substrate (either $100 \mu \mathrm{M}$ octanal, $200 \mu \mathrm{M}$ benzaldehyde, $200 \mu \mathrm{M}$ cinnamaldehyde or $1 \mathrm{mM}$ butyraldehyde)].

\section{RESULTS}

\section{Homologous recombination at the adhC locus of M. smegmatis}

To generate an M. smegmatis $\mathrm{AdhC}^{-}$mutant by gene replacement, the $a d h C$ coding region was interrupted at its unique NotI site by insertion of a kanamycinresistance marker gene (aphA-3). A one-step strategy (direct screening of DCOs) using the suicide vector pAGA6KM was used (Fig. 1). Plasmid DNA was pretreated with UV light to enhance the recombination frequency (Hinds et al., 1999) and used to electroporate M. smegmatis competent cells. To enable the selection of $M$. smegmatis cells that had undergone gene replacement events and reduce the number of colonies to be tested for DCOs, we used $s a c B$ and hyg as screening markers. Gene replacement events with looping-out of intervening plasmid sequences result in the loss of $s a c B$ and byg and render the organism resistant to sucrose and sensitive to hygromycin again. When used individually there are often problems with both of these markers. Spontaneous $\mathrm{Hyg}^{\mathrm{R}}$ mutant clones can be obtained (Parish et al., 1999), and though the sacB gene has previously been used for negative selection in mycobacteria (Pelicic et al., 1996a, b), problems have been reported with the high frequency of spontaneous sucrose resistance (Papavinasasundaram et al., 1998; Pavelka \& Jacobs, 1999). A second screening marker is thus desirable.

The $\operatorname{Kan}^{\mathrm{R}}$ colonies obtained were initially screened by plating them onto plates with $10 \%$ sucrose and plates containing hygromycin, to distinguish between integration events (SCOs or DCOs) and spontaneous $\mathrm{Kan}^{\mathrm{R}}$ arising after electroporation. Since the delivery vector we used is unable to replicate in mycobacteria, $\operatorname{Hyg}^{\mathrm{R}}$ $\mathrm{Suc}^{\mathrm{S}}$ clones were assumed to have integrated the plasmid into the chromosome by a SCO event. Analysis of the 150 transformants obtained showed that $51(34 \%)$ were straightforward DCOs and all the others were the result of SCOs. However, Southern blot analysis of eight of the DCO clones $\left(\mathrm{Kan}^{\mathrm{R}} \mathrm{Hyg}^{\mathrm{S}} \mathrm{Suc}^{\mathrm{R}}\right)$ with Padh after BamHI digestion did not confirm the expected genotype (Fig. 2a): hybridization resulted in two bands for all eight of the DCO candidate mutants. Although the $\sim 4000 \mathrm{bp}$ band that was consistent with a DCO event was present in each clone, we could also detect a $\sim 3300 \mathrm{bp}$ band that corresponded to the wild-type $a d h C$. When BamHIdigested DNA from these DCO clones was probed with
Pkan, only the $\sim 4000$ bp band was detected (Fig. 2b). On the other hand, when the blot was probed with PsacB no hybridization could be detected, confirming that the delivery vector had not been integrated into the chromosome of these clones, again suggesting a double recombination event (Fig. 2b).

The analysis of these results suggested that either the cassette from the delivery vector was integrated somewhere else in the chromosome, by illegitimate recombination or homologous recombination between two other sequences of the delivery vector, or the $a d h C$ gene was duplicated in the M. smegmatis genome. The illegitimate recombination possibility seemed very unlikely, as all the DCO clones had the same pattern when analysed by Southern blotting hybridization; however, we had no evidence that the analysed DCO events were actually homologous.

Analysis of some of the SCO clones showed that they resulted from a SCO event in the $a d b C$ coding region. Southern blot hybridization of eight SCO clones $\left(\operatorname{Kan}^{\mathrm{R}}\right.$ $\mathrm{Hyg}^{\mathrm{R}} \mathrm{Suc}^{\mathrm{S}}$ ) digested with BamHI (Fig. 2c), ApaI and BglII (data not shown) and probed with Padh (Fig. 2c) revealed two types of SCO mutant, and it was possible to determine that they corresponded to SCO events that took place either upstream or downstream of the $a d h C$ gene (Fig. 2d). In the latter case an unexpected band was found to hybridize to Padh. It is possible that a wild-type $a d h C$ was also present in the clones in which the SCO event occurred upstream of $a d b C$; however, since the band generated was the same size as the one generated by the BamHI fragment containing the wild-type $a d b C$ ( $3300 \mathrm{bp}$ ), only one band, corresponding to two DNA fragments, could be seen. These results argue against the existence of sequences other than $a d h C$ that are homologous to the plasmid in the M. smegmatis genome, and provide preliminary evidence that $a d h C$ could be duplicated within the M. smegmatis genome.

To confirm the duplication hypothesis, we repeated the electroporation of $M$. smegmatis competent cells with the delivery vector, using a two-step screening strategy. This enabled the selection of DCOs resulting from a second SCO event in a homologous SCO clone. If $a d h C$ was not an essential gene, a second cross-over event should have occurred in some of the SCO clones to generate a DCO clone in which $a d b C$ had been replaced by a disrupted copy of the gene. The presence of a nondisrupted copy of $a d h C$ together with a disrupted copy would confirm the hypothesis.

One of the SCO mutants selected on plates containing kanamycin and hygromycin, after having been characterized by Southern hybridization as a homologous SCO (data not shown), was picked and streaked out onto plates lacking antibiotics. Following cultivation, a loopful of cells was resuspended in liquid medium and serial dilutions were plated onto a sucrose-enriched medium to select for clones that had lost the integrated plasmid through a second SCO. Suc ${ }^{\mathrm{R}}$ colonies were streaked onto kanamycin plates with and without 
(a)

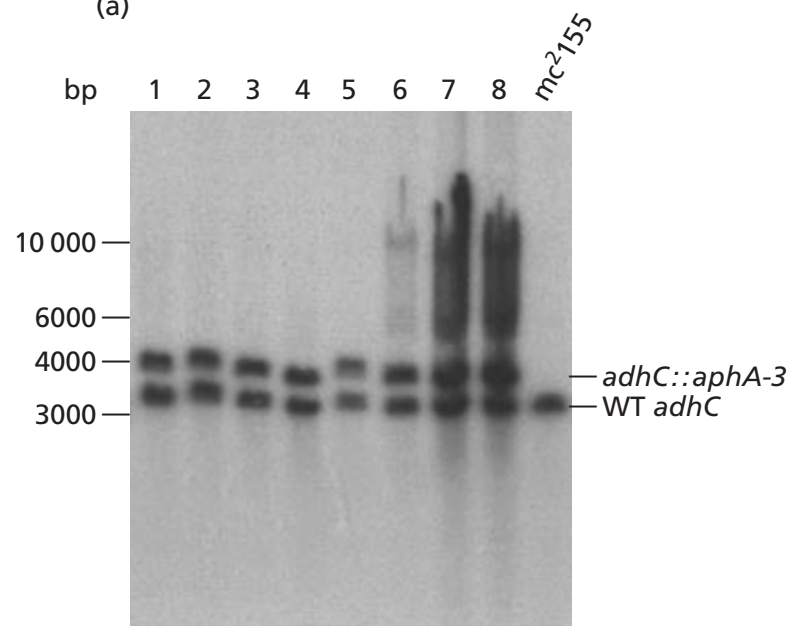

(d) (b)

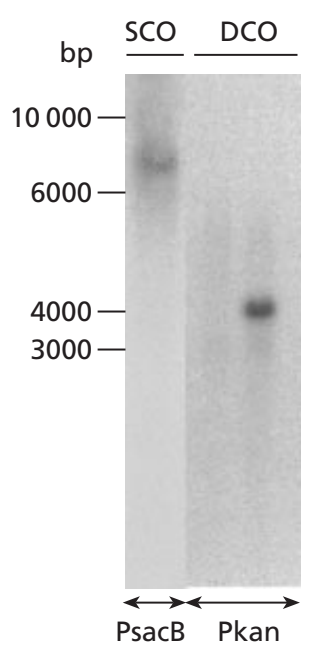

(c)

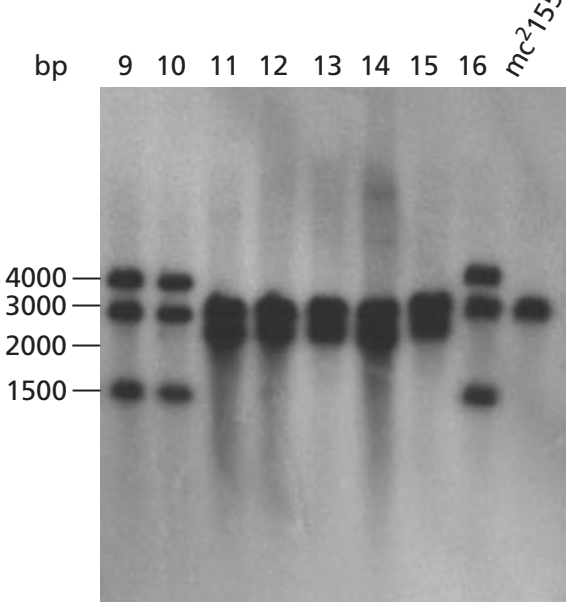

\section{SCO upstream}

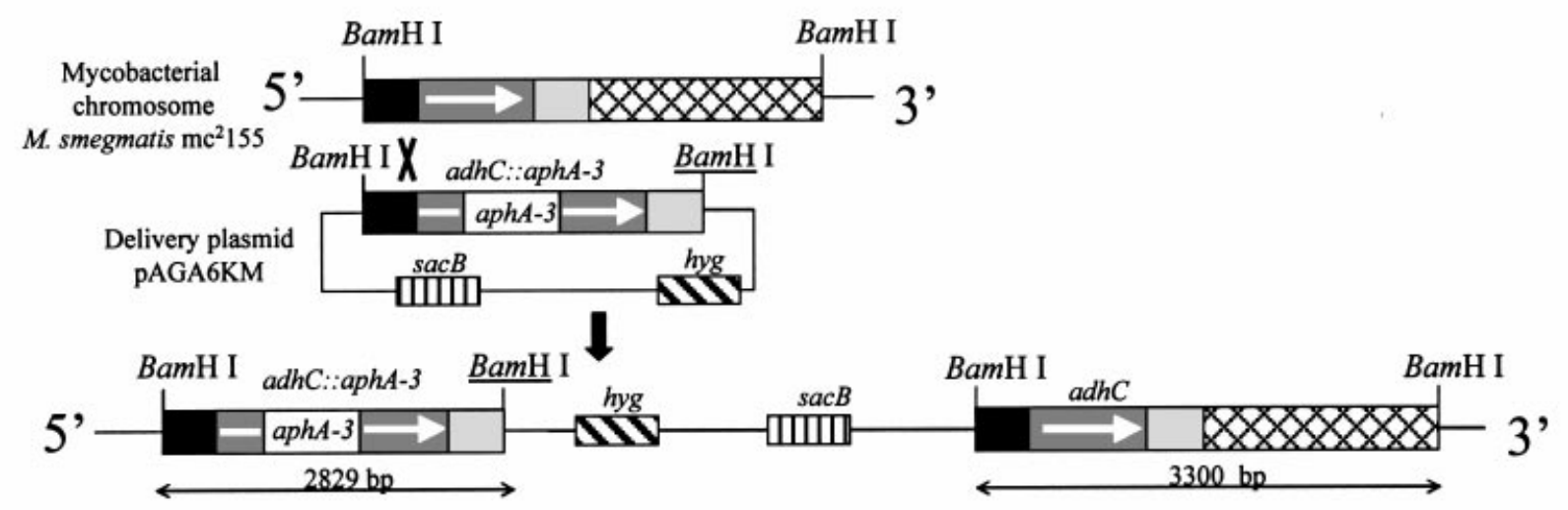

\section{SCO downstream}

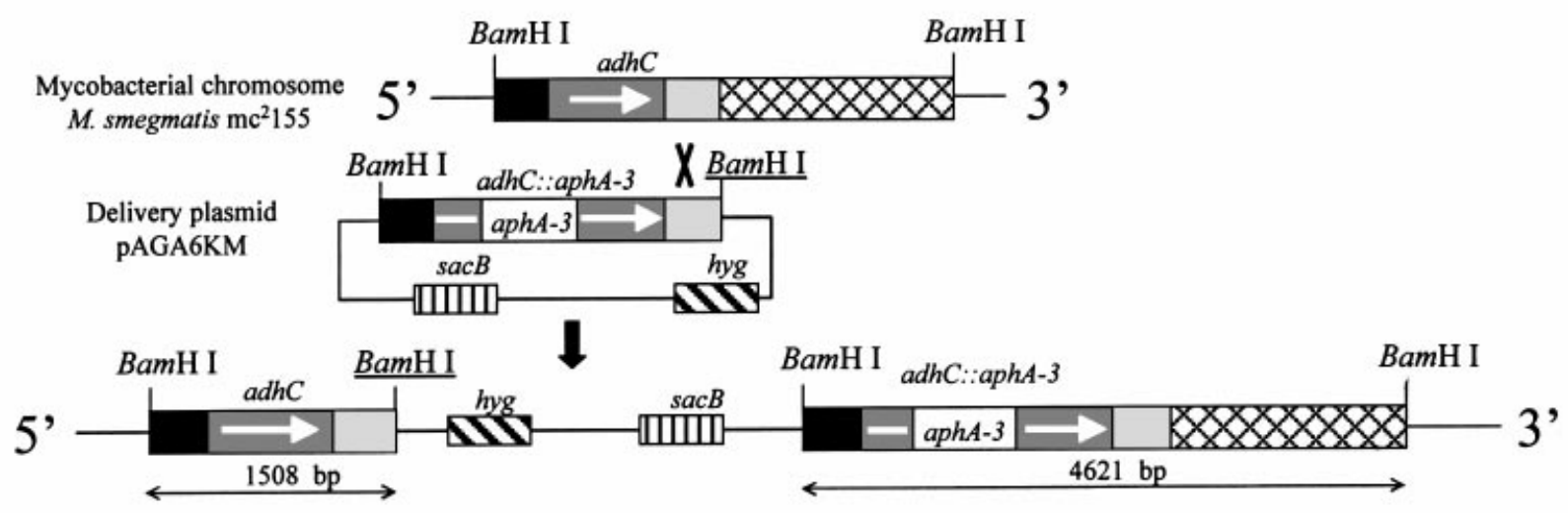

$\operatorname{adhC}$ (ORF)

$a d h C$ upstream flanking region

XX $a d h C$ downstream flanking region

(not included in the delivery plasmid)

adhC downstream flanking region (included in the delivery plasmid)
$\begin{array}{ll}\prod_{\operatorname{sacB}}^{a p h A-3} & \mathbf{W} \text { hyg } \\ \prod & \end{array}$

Fig. 2. Southern blot analysis of the adhC locus of representative clones resulting from homologous recombination with pAGA6KM. The clones were obtained by a one-step selection on agar plates containing sucrose and hygromycin. (a) 

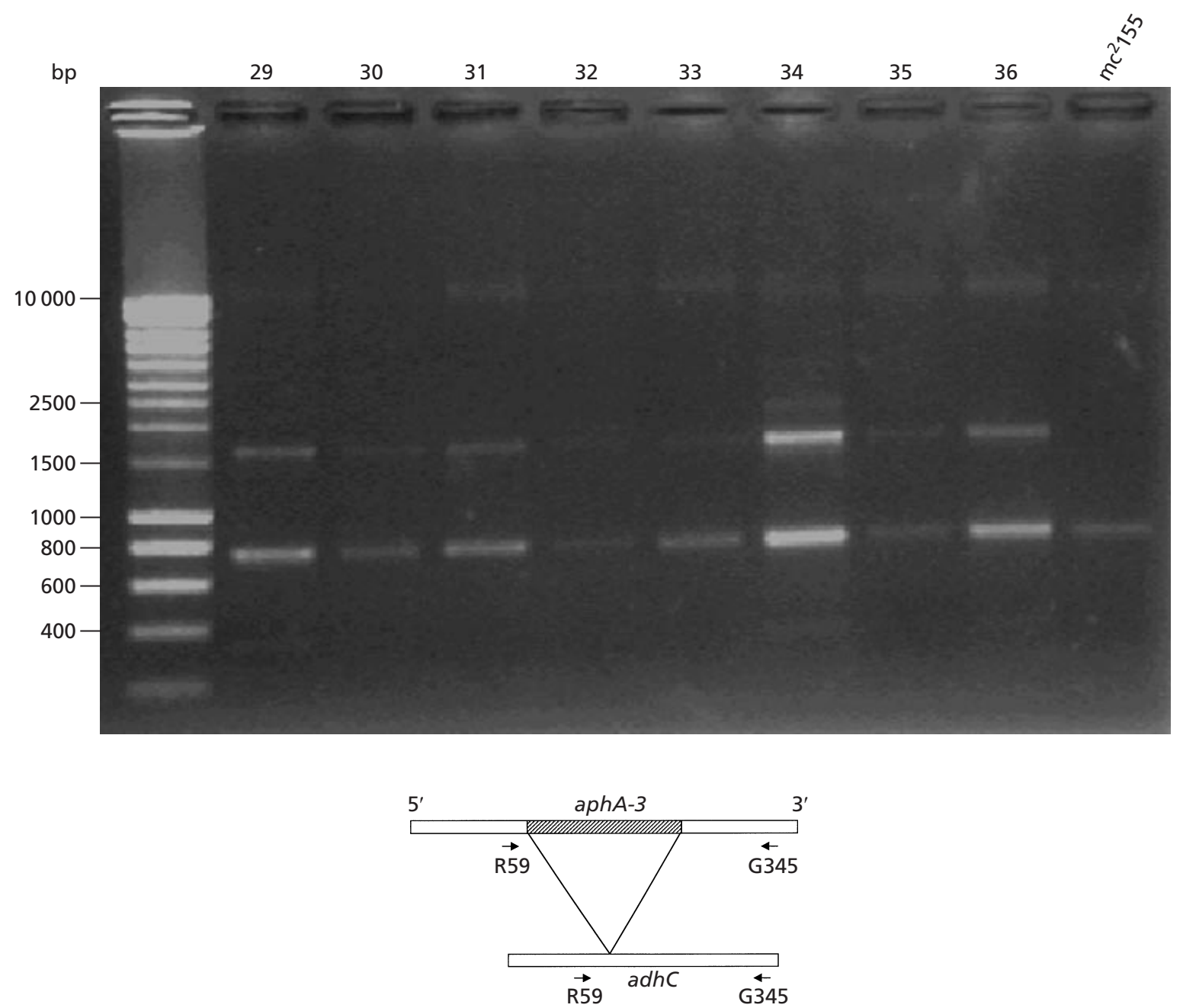

Fig. 3. $P C R$ analysis of eight representative $\mathrm{Kan}^{R} \mathrm{Hyg}^{S} \mathrm{Suc}^{\mathrm{R}}$ clones (nos 29-36) which resulted from homologous recombination with pAGA6KM. Altogether 100 clones were screened by PCR. The $\mathrm{Kan}^{R} \mathrm{Hyg}^{\mathrm{S}} \mathrm{Suc}^{\mathrm{R}}$ clones were obtained by a two-step selection on agar containing sucrose and hygromycin. PCR amplification was performed with primers R59 and G345. A $760 \mathrm{bp}$ fragment was expected to be amplified from AdhC $^{+}$strains and a 1500 bp fragment from AdhC ${ }^{-}$ strains. Bands of $760 \mathrm{bp}$ and $1500 \mathrm{bp}$ were detected in each of the DCO mutants, suggesting the presence of two copies of the adhC gene within the M. smegmatis genome. As a control, PCR was performed on wild-type M. smegmatis $\left(\mathrm{mc}^{2} 155\right)$, resulting in the amplification of a $760 \mathrm{bp}$ fragment.

hygromycin, and scored for growth to distinguish DCOs from SCOs which had acquired spontaneous resistance to sucrose. One hundred $\mathrm{Kan}^{\mathrm{R}} \mathrm{Hyg}^{\mathrm{S}} \mathrm{Suc}^{\mathrm{R}}$ colonies were analysed by PCR (Fig. 3), but again both the 760 and
$1500 \mathrm{bp}$ bands were detected in each DCO mutant. Some of these clones were further analysed by Southern blotting, using the probes Padh and Pkan, which confirmed the results obtained by PCR (data not shown).

BamHI-digested DNA from M. smegmatis wild-type $\left(\mathrm{mc}^{2} 155\right)$ and eight DCO clones $\left(\mathrm{Kan}^{\mathrm{R}} \mathrm{Hyg}^{\mathrm{S}}\right.$ Suc ${ }^{\mathrm{R}}$ ) hybridized to the Padh probe (adhC from pAGA5). (b) BamHI-digested DNA from one DCO clone (Kan ${ }^{R} \mathrm{Hyg}^{\mathrm{S}} \mathrm{Suc}^{\mathrm{R}}$ ) probed with both PsacB (hsp60-sacB from pAGA6KM) and Pkan (aphA-3 from pUC18K). BamHI-digested DNA from a SCO clone was also probed with PsacB and was used as a hybridization control. The BamHI fragment from the SCO clone which contained sacB has 7400 bp. (c) BamHI-digested DNA from M. smegmatis wild-type and eight $\mathrm{Kan}^{\mathrm{R}} \mathrm{Hyg}^{\mathrm{R}} \mathrm{Suc}^{\mathrm{S}}$ clones probed with Padh. Clones 9, 10 and 16 correspond to SCO events that took place downstream of the adhC coding region; clones $11,12,13$, 14 and 15 correspond to SCO events that took place upstream of the adhC coding region. (d) Schematic interpretation of the results shown in (c). Upper panel, a homologous SCO event upstream of the adhC coding region integrates the delivery vector into the chromosome in such a way that after BamHI digestion, two fragments of $2829 \mathrm{bp}$ and $3300 \mathrm{bp}$ are obtained; Lower panel, when the homologous SCO event occurs downstream of the adhC coding region two fragments are obtained after BamHI digestion (1508 bp and $4621 \mathrm{bp}$ ). The underlined BamHI site does not exist in the genomic $M$. smegmatis DNA and was added during the construction of the delivery vector. 
These results, together with the Southern blotting and PCR results for the first set of DCO mutants, strongly suggested that there were two copies of $a d h C$ in the $M$. smegmatis genome and that the DCO clones obtained with both screening strategies have the phenotype $\mathrm{AdhC}^{+/-}$.

Southern hybridizations were carried out on genomic DNA from wild-type $M$. smegmatis which had been digested with several different restriction enzymes (among them ApaI, BglII, EcoRV and SphI). The blots repeatedly showed one single band for each of the enzymes when probed with Padh (results not shown). This suggested that the duplicated region, if any, should be bigger than the fragments generated when $M$. smegmatis DNA was digested with these different enzymes, i.e. 3-6 kb.

The definitive proof of the $a d b C$ duplication in the $M$. smegmatis genome was obtained when a clone in which two DCO events had occurred was isolated. Competent cells from clone 31, one of the first DCO mutants, were prepared and electroporated with the suicide delivery vector pAGA6KM. A two-step strategy was followed to screen DCO mutants, as the cells were already $\operatorname{Kan}^{\mathrm{R}}$ and it was not possible to use kanamycin as the only selectable marker. SCO events were first selected on plates containing kanamycin and hygromycin; a second SCO was subsequently screened for by using the $s a c B$ and byg genes. Five SCO mutants were picked and streaked out onto plates lacking antibiotics. Following growth, a loopful of cells was resuspended in liquid medium and serial dilutions were plated onto a sucroseenriched medium. Seventy Suc ${ }^{\mathrm{R}}$ colonies were streaked onto kanamycin plates with and without hygromycin to select for DCO mutants. Forty-nine $\mathrm{Kan}^{\mathrm{R}} \mathrm{Hyg}^{\mathrm{S}} \mathrm{Suc}^{\mathrm{R}}$ clones were selected and 27 were analysed by PCR. Among the tested clones only one (clone 18) showed the expected genotype for a double DCO event. The genomic DNA from this clone was extracted and analysed by Southern blotting (Fig. 4a). The probe Padh was used and was found to hybridize only to one BamHI DNA fragment of $\sim 4000 \mathrm{bp}$, which confirmed that the $\sim 3300 \mathrm{bp}$ band has been removed to become $\sim 4000$ $\mathrm{bp}$, as expected from disruption of the second $a d b C$ gene. These results also demonstrated that $a d h C$ is not an essential gene for M. smegmatis.

Southern hybridizations of genomic DNA from $M$. smegmatis wild-type and from clone 31 digested with Bam HI were performed using the probe Pdws, a $1230 \mathrm{bp}$ flanking region downstream of the $a d h C$ gene in $M$. smegmatis (Fig. 4b). This fragment is not present in the delivery vector pAGA6KM, but was initially cloned into pAGA5, and was used to verify whether the downstream flanking regions of the two $a d h C$ copies were the same. A band corresponding to $\sim 3300 \mathrm{bp}$ was obtained for the M. smegmatis wild-type strain, whereas two bands corresponding to $\sim 3300 \mathrm{bp}$ and $\sim 4000 \mathrm{bp}$ were obtained for the DCO clone. These findings indicated that M. smegmatis is merodiploid for $a d h C$ and probably for a certain number of neighbouring genes. It was
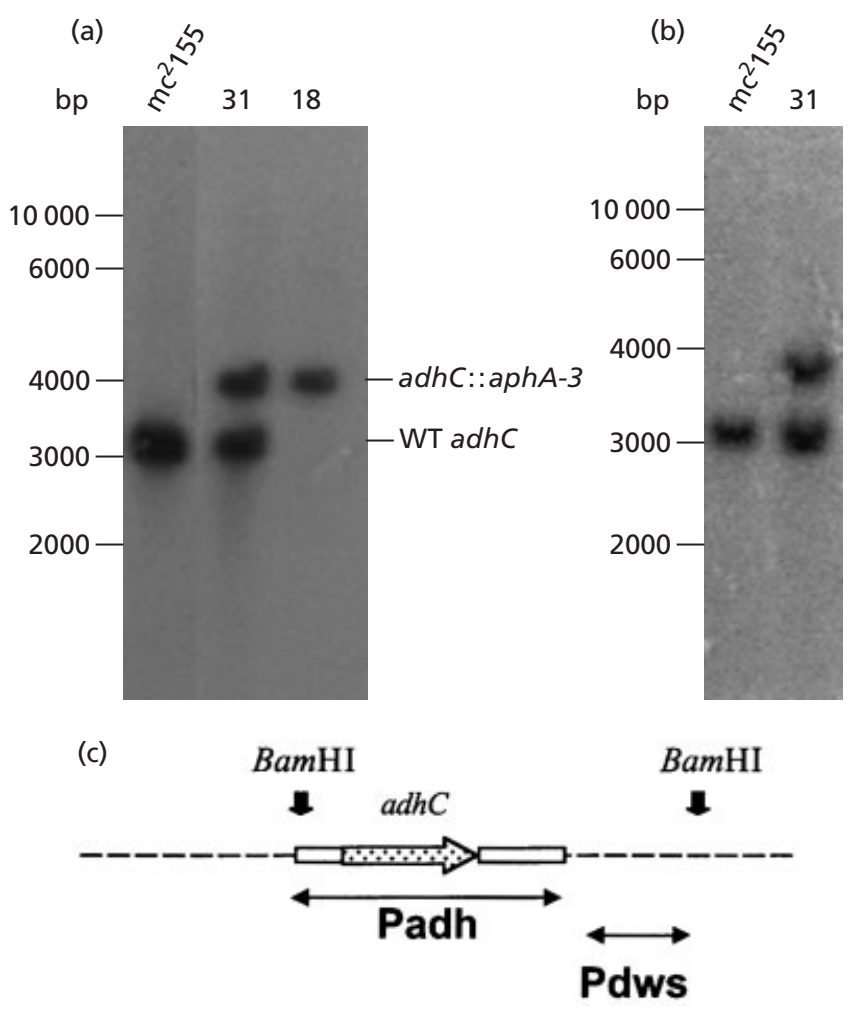

Fig. 4. Southern blot of BamHI-digested DNA from clone 31 $\left(\mathrm{AdhC}^{+-}\right)$, clone $18\left(\mathrm{AdhC}^{-1-}\right.$ ) and $M$. smegmatis $\mathrm{mc}^{2} 155$. (a) BamHI-digested DNA from wild-type $M$. smegmatis $\left(\mathrm{mc}^{2} 155\right)$, clone 31 and clone 18 hybridized to the Padh probe. Padh only hybridized to one $\sim 4000 \mathrm{bp}$ fragment for clone 18, indicating that the $\sim 3300 \mathrm{bp}$ adhC coding regions had been disrupted by insertion of the aphA-3 cassette. (b) BamHI-digested DNA from wild-type $M$. smegmatis $\left(\mathrm{mc}^{2} 155\right)$ and clone 31 probed with Pdws. Pdws was used to verify whether or not the downstream flanking regions of the two copies of adhC were the same. Clone 31 (DCO mutant) produced two bands ( $23300 \mathrm{bp}$ and $\sim 4000 \mathrm{bp}$ ) which indicated that $M$. smegmatis is merodiploid for adhC and possibly for a certain number of neighbouring genes. (c) Schematic representation of the binding sites for the probes Padh and Pdws.

not possible to check the region upstream of $a d h C$ for merodiploidy, as the known upstream sequence of $a d h C$ was included in the delivery vector, pAGA6KM.

\section{PFGE to determine the position of the two adhC genes}

To determine the localization of the two $a d h C$ genes and obtain information about the size of this duplication in the M. smegmatis genome, agarose plugs containing DNA from M. smegmatis wild-type, clone 31 and clone 18, were digested with DraI and resolved by PFGE. By comparative Southern blot hybridization analysis, and thanks to the DraI restriction site in the kanamycin cassette used to disrupt the $a d h C$, it was possible to obtain some information about the duplication within the M. smegmatis genome. Southern blot hybridization with P600, a $760 \mathrm{bp}$ fragment of the ADHC ORF 


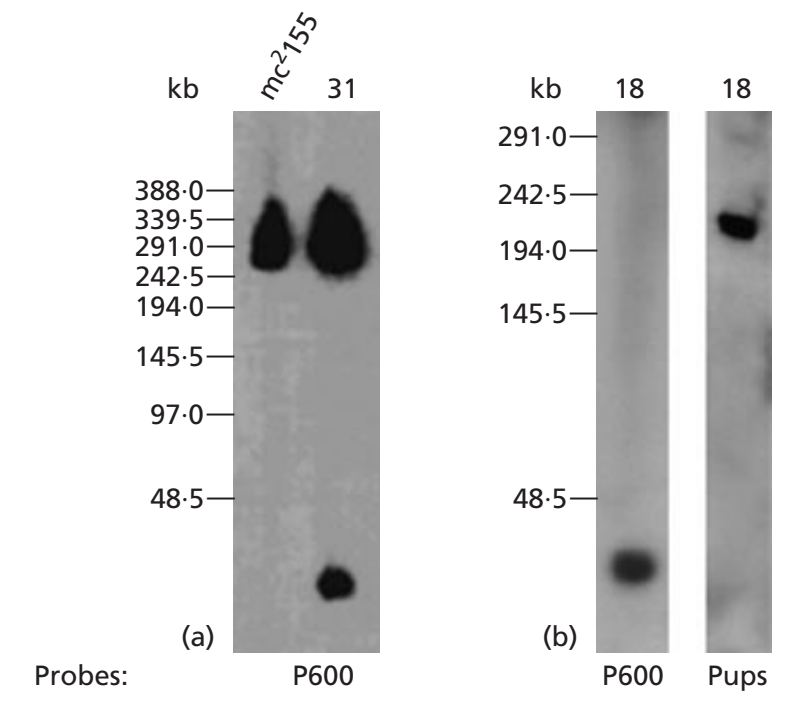

(c)
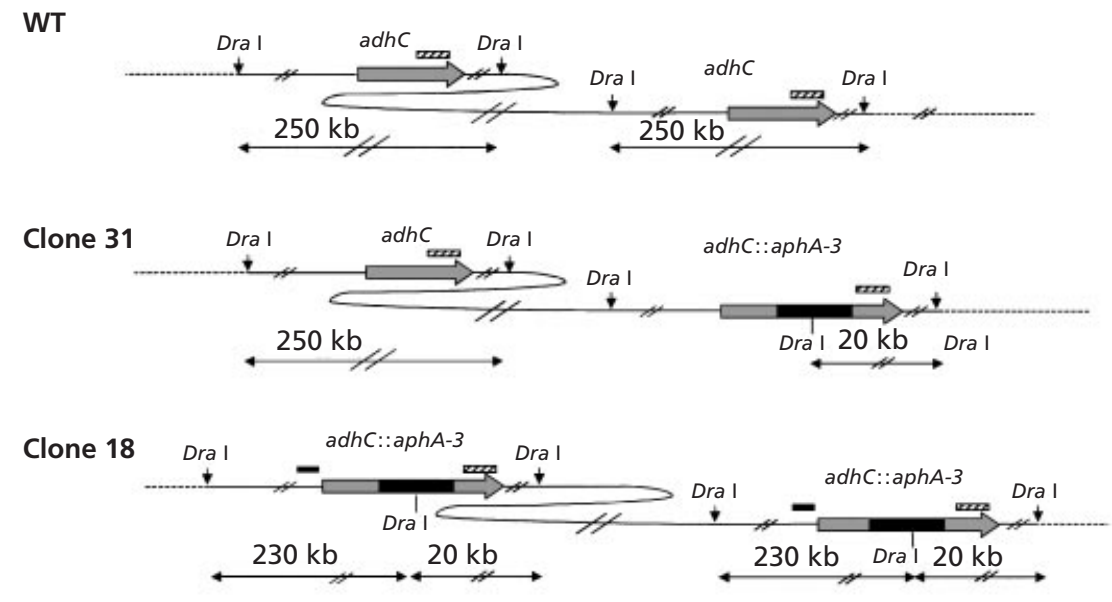

downstream of the site where the kanamycin cassette containing the DraI had been inserted, revealed that each $a d h C$ of $M$. smegmatis wild-type was within a $\sim 250 \mathrm{~kb}$ DraI DNA fragment. On the other hand, $\sim 250 \mathrm{~kb}$ and $\sim 20 \mathrm{~kb}$ fragments from clone 31, and a $\sim 20 \mathrm{~kb}$ fragment from clone 18, were found to hybridize with P600 (Fig. 5a, b). The hybridization of the DraI-digested DNA from clone 18 with Pups, a $343 \mathrm{bp}$ fragment upstream of adhC, revealed a $\sim 230 \mathrm{~kb}$ fragment (Fig. 5b). Though our results do not allow us to determine the exact size of this duplication, it may be at least $\sim 250 \mathrm{~kb}$. Fig. $5(\mathrm{c})$ shows our proposed interpretation of the results obtained by PFGE. We propose the existence of a tandem duplication as the most probable explanation; however, even if the duplication is not in tandem this does not affect the predicted size of the duplication found within the M. smegmatis genome. The relative position of both of the copies of $a d h C$ in the DraI fragments is shown in Fig. 5(c). The $\sim 250 \mathrm{~kb}$ band obtained with $\mathrm{P} 600$ on M. smegmatis wild-type DNA, the $\sim 20 \mathrm{~kb}$ band obtained with P600 on clone $18 \mathrm{DNA}$, and the $\sim 230 \mathrm{~kb}$ band obtained with Pups on clone 18 should correspond to two DraI DNA fragments each.

\section{SDS-PAGE and Western blot analysis of the M. smegmatis $\mathrm{Adh}^{+/-}$and $\mathrm{Adh}^{-/-}$mutants}

To verify whether the chromosomal mutations in $a d h C$ disrupted the synthesis of ADHC, lysates from $3 \mathrm{~d}$ pellicles of wild-type M. smegmatis and both recombinant strains were prepared, resolved by SDS-PAGE, and immunoblotted with 4B5, a murine monoclonal antibody raised against BCG-ADHC. As shown in Fig. 6, 


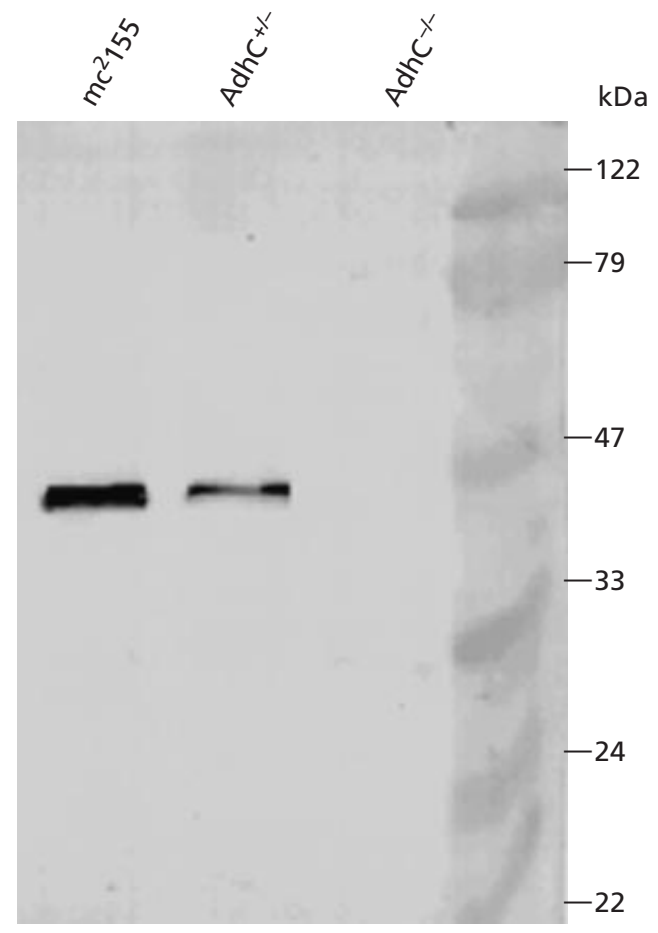

Fig. 6. Detection of $A D H C$ synthesis in extracts from $M$. smegmatis $\mathrm{mc}^{2} 155, M$. smegmatis $\mathrm{AdhC}^{+/-}$and $M$. smegmatis $\mathrm{AdhC}^{-1-}$ by Western blot analysis. Two micrograms of protein were separated on a $12 \%$ SDS-PAGE, electroblotted and detected by incubation with a murine monoclonal antibody (4B5) raised against the BCG-ADHC. a single band of $38 \mathrm{kDa}$, corresponding to the ADHC, was found in extracts from M. smegmatis wild-type and from clone 31, the M. smegmatis $\mathrm{AdhC}^{+/-}$mutant. However, this band was absent in lysates of the clone 18 , the M. smegmatis $\mathrm{AdhC}^{-1-}$ mutant. The band corresponding to the M. smegmatis $\mathrm{AdhC}^{+/-} \mathrm{ADHC}$ was fainter than the one from the wild-type strain, which indicates that in this mutant strain ADHC is expressed at a lower level than in the wild-type M. smegmatis strain. These results confirmed the results from the genetic experiments, suggesting the existence of two functional copies of adhC in M. smegmatis $\mathrm{mc}^{2} 155$.

\section{In vitro growth studies}

The parent and mutant strains were cultivated in supplemented Middlebrook 7H9 broth (see Methods). The growth rate of both $M$. smegmatis $\mathrm{AdhC}^{+/-}$and $M$. smegmatis $\mathrm{AdhC}^{-/-}$were reduced when compared with the $M$. smegmatis wild-type, suggesting a growth disadvantage associated with the loss of expression of one or two $a d h C$ copies. On supplemented Middlebrook 7H10 broth, mutant strains produced after $2 \mathrm{~d}$ growth colonies with a different morphology when compared with the colonies produced by the wild-type strain (data not shown). However, the mutants were still acid-fast. Static cultures grown on Sauton medium from each of the mutants showed that pellicles from the knockout strains were less folded and more inclined to sink than the ones produced by the wild-type M. smegmatis (data not shown).
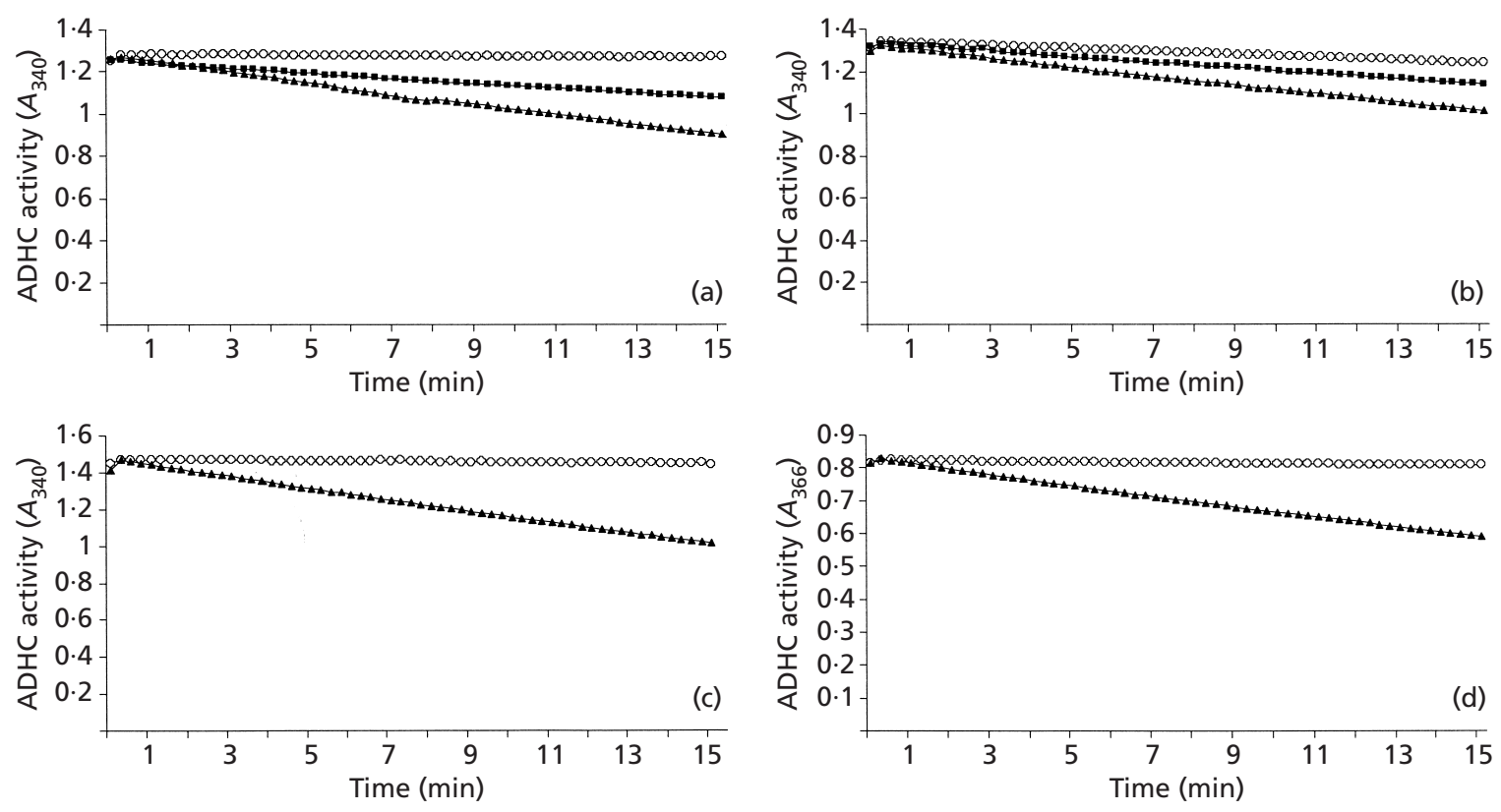

Fig. 7. Assay of the $A D H C$ activity of $M$. smegmatis $\mathrm{mc}^{2} 155, \mathrm{AdhC}^{+/-}$and $\mathrm{AdhC}^{-/-}$. Strains were grown as surface pellicles for $3 \mathrm{~d}$, recovered by filtration, sonicated and centrifuged. The protein concentration within the cell lysates was determined using the method of Spector (1978) with BSA as a standard. ADHC activity was measured in $1 \mathrm{ml}$ reaction mixtures containing $0.02 \mathrm{M} \mathrm{KH}_{2} \mathrm{PO}_{4} / \mathrm{Na}_{2} \mathrm{HPO}_{4}$ buffer $(\mathrm{pH} 7 \cdot 3), 0.25 \mathrm{mM} \mathrm{NADPH}, 25 \mu \mathrm{g}$ total protein extracted from $M$. smegmatis $\mathrm{mc}^{2} 155(\mathbf{A})$, M. smegmatis $\mathrm{AdhC}^{+-1}(\boldsymbol{\nabla})$ or M. smegmatis $\mathrm{AdhC}^{-1-}(\mathrm{O})$, and (a) $200 \mu \mathrm{M}$ benzaldehyde, (b) $100 \mu \mathrm{M}$ octanal, (c) $1 \mathrm{mM}$ butyraldehyde or (d) $200 \mu \mathrm{M}$ cinnamaldehyde. ADHC activity was expressed as oxidation of $0.25 \mathrm{mM}$ $\mathrm{NADPH}$ at $A_{340}$ (benzaldehyde, octanal and butyraldehyde) or at $A_{366}$ (cinnamaldehyde). 


\section{Biochemical characterization of the $M$. smegmatis $\mathrm{AdhC}^{+/-}$and $\mathrm{AdhC}^{-/-}$mutants}

Lysates from $3 \mathrm{~d}$ pellicles of wild-type $M$. smegmatis and both recombinant strains were obtained, and $\mathrm{ADH}$ specific activity was determined by measuring the rate of oxidation of $0.25 \mathrm{mM} \mathrm{NADPH}$ at $A_{340}$ in the presence of concentrations of octanal and benzaldehyde well above the $K_{\mathrm{m}}$ that had been previously determined for the Ms-ADHC in vitro (Galamba et al., 2001). These two substrates had previously been shown to be, in vitro, the best available substrates for this enzyme. As can be seen in Fig. $7(\mathrm{a}, \mathrm{b})$ the M. smegmatis $\mathrm{AdhC}^{-1-}$ could not reduce either of these two aldehydes, while M. smegmatis $\mathrm{AdhC}^{+/-}$showed intermediate activities for both benzaldehyde and octanal, when compared with the $M$. smegmatis wild-type and M. smegmatis $\mathrm{AdhC}^{-/-}$. We also tested $M$. smegmatis $\mathrm{AdhC}^{-/-}$with two other aldehydes, butyraldehyde and cinnamaldehyde, but neither of them was reduced by the $M$. smegmatis AdhC $^{-1-}$ lysates (Fig. 7c, d). The absence of activity in the double-knockout mutant could be explained either by the fact that ADHC is the only M. smegmatis $\mathrm{ADH}$ which uses NADPH as a cofactor, or that the other putative ADHs which can be deduced from the $M$. smegmatis genome sequence available (http://www.tigr.org/tdb/mdb/mdbinprogress.html) are either not expressed or are inactive in our crude bacterial extracts.

\section{DISCUSSION}

\section{M. smegmatis ADHC mutants}

The ability to inactivate genes by homologous recombination is a key requirement to study the function of individual genes. Although gene replacement in $M$. smegmatis is relatively efficient, some problems in getting gene mutations by standard gene replacement methods have been reported (Hinds et al., 1999). Pretreatment of the DNA vector with UV light and the utilization of counter-selection markers have been described as useful methods to efficiently generate and screen mutants by allelic replacement. The former was reported to stimulate homologous recombination and abolish illegitimate recombination in recipient cells (Hinds et al., 1999), and the latter was reported to enable the distinction of SCO, DCO and illegitimate recombination events (Parish \& Stoker, 2000). In this study we used a UV-denatured suicide delivery vector containing the $a d h C$ gene disrupted by a kanamycin cassette, which prevents polar effects from the inserted antibioticresistance marker (Menard et al., 1993). The delivery vector used to electroporate $M$. smegmatis $\mathrm{mc}^{2} 155$ competent cells also contains two screening markers, byg and $s a c B$.

The initial attempts to select an ADHC knockout mutant were unsuccessful, though a large number of DCO mutants were generated. The one-step strategy initially used can be useful to generate marked mutations, but in some cases the required mutants will not be obtained, e.g. if the gene is essential or the recombination frequency at the locus is low. In these cases, especially for slow-growing mycobacteria, where gene replacement has not proved to be straightforward (McFadden, 1996), a two-step strategy has been usually employed, whereby SCO events were first selected, and then screening for the second cross-over was carried out to yield the mutant strains. We thus decided to switch to a two-step strategy that should ensure that the DCO clones selected are homologous, and also help determine whether $a d b C$ is duplicated. DCO mutants were obtained from SCO clones where another recombination event had taken place. These DCO mutants were characterized and found to have the same genotype as the DCO mutants previously obtained with the one-step strategy. They were further characterized by Western blotting (data not shown) and seemed to have less ADHC present than the wild-type $M$. smegmatis. Altogether, our results provided strong evidence that there are two copies of the $a d b C$ in $M$. smegmatis $\mathrm{mc}^{2} 155$.

This hypothesis was confirmed when competent cells of one DCO mutant were prepared and another DCO event was selected from this strain, using a two-step strategy. This led us to isolate one clone which, by both PCR and Southern blot hybridization analysis, was shown to have the two copies of $a d h C$ replaced by two disrupted copies. Western blot hybridization results confirmed the results obtained by Southern blot hybridizations. Thus, a defective mutant unable to express ADHC was only obtained when two functional native $a d h C$ copies were disrupted by homologous recombination.

These results showed that $a d h C$ is not an essential gene for the in vitro growth of $M$. smegmatis. Surprisingly, we observed a difference in the growth and morphology for both M. smegmatis AdhC ${ }^{+/-}$and $\mathrm{AdhC}^{-1-}$ when compared with the wild-type $\mathrm{AdhC}^{+/+}$strain. In the absence of further information about the physiological role of the ADHC enzyme these observations are difficult to explain.

The preliminary biochemical characterization of the $M$. smegmatis $\mathrm{AdhC}^{+/-}$and $\mathrm{AdhC}^{-/-}$mutants did not help us to find out which aldehydes are closest to the ones used in vivo by this mycobacterial $\mathrm{ADH}$, as the $\mathrm{AdhC}^{-1-}$ knockout mutant does not use any of the structurally different substrates tested. Preliminary analysis of the lipid and aldehyde contents of the mutant strains compared to the wild-type M. smegmatis strain has not yet shown any significant differences.

\section{M. smegmatis $\mathrm{mc}^{2} 155$ genome duplication}

Evidence accumulated during the generation of the $M$. smegmatis $\mathrm{mc}^{2} 155$ adhC knockout mutants uncovered a large duplication in its genome. PFGE, which enables the separation of large DNAs and can be used to investigate genome organization, was used to obtain information about the duplication extension and 
localization. Although PFGE is routinely used in many mycobacterial species, we were not successful in analysing M. smegmatis DNA by PFGE when using the classical protocols for mycobacteria (Levy-Frebault et al., 1989; Philipp et al., 1996). Similar difficulties had been previously described for the analysis of Streptomyces lividans DNA (Ray et al., 1992), and were associated with Tris-dependent site-specific cleavage of the DNA. Tris-derived nucleolytic species have been shown to react with thiourea, which could thus protect the DNA from strand cleavage (Evans \& Dyson, 1993). We achieved non-degradative PFGE of the M. smegmatis DNA only when $50 \mu \mathrm{M}$ thiourea was added to the running buffer. Southern blot analysis of DraI-digested genomic DNA from M. smegmatis $\mathrm{mc}^{2} 155$, clone 31 and clone 18 resolved by PFGE demonstrated that $M$. smegmatis $\mathrm{mc}^{2} 155$ harbours a large chromosomal duplication whose size may be at least $\sim 250 \mathrm{~kb}$. Our results did not prove that the whole $\sim 250 \mathrm{~kb}$ region was duplicated; however, DraI sites are relatively rare in mycobacteria and it seems quite unlikely that two DraI sites would exist in the M. smegmatis genome at the same distance from the two adhC genes, even if they did not belong to a duplicated region. The chances of the existence of two identical (same size and sequence) fragments running together in the gel is much greater than the existence of two fragments of the same size, but with different sequences. Thus, the size of the duplication found in the M. smegmatis genome could be at least $\sim 250 \mathrm{~kb}$.

Chromosomal duplication and resultant gene duplication are ubiquitous features of genome evolution and have been viewed as the predominant mechanisms for the evolution of new gene functions and adaptive responses (Lupski et al., 1996). Chromosomal duplications provide a means for increasing gene dosage and for generating novel functions from potential gene fusion events at duplication end points, and represent a source of redundant DNA for divergence. Over half of the proteins present in the tubercle bacillus have arisen from ancient gene duplication and adaptation events (Cole et al., 1998; Tekaia et al., 1999).

The generally accepted model for the formation of chromosomal duplication in bacteria is that, after chromosomal replication, misaligned repeated sequences (e.g. rrn operons, IS elements, transposons) (Lupski et al., 1996) or short DNA homologies (Edlund \& Normark, 1981) act as substrates for homologous recombination, leading to duplication or deletion of the specific region between the repeated sequences. The duplicated regions are usually flanked by repeated sequences in a directed orientation, and duplication formation is generally found to be highly dependent on the RecA function. Certain duplications have been observed which confer a growth advantage under specific selective conditions and play a role in the adaptation of micro-organisms as a method for gene amplification. When conditions arise which cannot be compensated for by an alteration in gene expression, either in the laboratory or in nature, selection may favour an increase in the copy number of a gene or a group of genes. In general these duplications are rather large, up to one-third of the chromosome, but they are highly unstable as they are typically tandem duplications and are lost by homologous recombination when environmental conditions change, thus representing a readily reversible source of genomic variation (Anderson \& Roth, 1977). Spontaneous tandem chromosomal duplications are common in populations of E. coli and Salmonella typhimurium (Haack \& Roth, 1995).

The existence of two tandem chromosomal duplications of the genome of M. bovis BCG Pasteur, DU1 (29668 bp) and DU2 (36161 bp) (Brosch et al., 2000) was recently reported and showed that these genomic regions of the BCG genome are still dynamic. This study concluded that BCG Pasteur is diploid for at least 58 genes and that at a certain point in its evolution contained duplicate copies of a further 60 genes which were lost when a deletion internal to DU2 arose.

The presence of a large $(>250 \mathrm{~kb})$ cis duplication in the M. smegmatis genome is described here for the first time. An amplification has already been described in $M$. smegmatis, in the gene $p s t B$, encoding the putative ATPase subunit of the phosphate-specific transporter system, in a fluoroquinolone-resistant $M$. smegmatis strain (Bhatt et al., 2000). However, this is one of those cases where selection for increased gene dosage resulted in spontaneous amplification of one gene and there was no evidence that other flanking genes were duplicated or amplified.

We cannot exclude the possibility that the duplication we describe here had originated as the result of specific environmental conditions, but this is certainly a large chromosomal duplication that includes many genes. We propose that the duplication we found is a tandem duplication because non-tandem or inverted duplications appear to be very rare compared with the tandem ones. In fact, most of the duplications that have been analysed in detail in bacteria appear to be tandem duplications (Anderson \& Roth, 1977, 1981; Brosch et al., 2000; Heath, 1992). The restriction analysis of $M$. smegmatis DNA with several restriction enzymes showed that this M. smegmatis chromosomal duplication is probably a recent one in which divergence of gene sequences has not yet occurred. The mechanism responsible for this duplication is still obscure. Since the assembled complete genome sequence of $M$. smegmatis is not yet available, we do not know which sequences could have been involved in the recombination event that originally generated this duplication.

A preliminary study of the sequencing and assembly of the complete M. smegmatis genome indicates that this, at nearly $7 \mathrm{Mbp}$, is approximately $50 \%$ larger than that of its slow-growing relatives (Merkel et al., 2001). Since the genome sequence of $M$. smegmatis was based upon sequencing shotgun clones which do not detect possible genomic duplications or other genomic rearrangements, the previewed size for the genome of this mycobacterial species might have been underestimated. Bacterial arti- 
ficial chromosome (BAC) libraries, representing the complete genome of $M$. smegmatis, could be used for detection and localization of other possible duplications. Quantitative DNA-DNA hybridization has also been reported as a method which allows accurate determination of the size of merodiploid chromosomes and the identification of genes present in two copies per chromosome (Hauser \& Karamata, 1994).

Future strategies for disruption of M. smegmatis genes should consider the possibility of having to mutate more than one gene copy. Availability of the assembled complete genome sequence from $M$. smegmatis will enable the determination of which genes are included within the $\sim 250 \mathrm{~kb}$ duplicated region, but additional techniques (such as BACs or heteroduplex mapping) will be needed to determine its exact size, orientation and origin, and to detect other duplications and other possible complex genomic rearrangements within the M. smegmatis genome.

\section{ACKNOWLEDGEMENTS}

We are grateful to Tanya Parish and Neil Stoker for generously supplying pGOAL19 and helpful suggestions, and to Robert Menard for providing pUC18K. We are also grateful to Ariane Deplano, Sabrina Damée and Eddie Van Bossuyt for their helpful advice with the PFGE experiments. This work was supported by grant BD/9181/96 from Fundação para a Ciência e Tecnologia, Portugal.

\section{REFERENCES}

Anderson, R. P. \& Roth, J. R. (1977). Tandem genetic duplications in phage and bacteria. Annu Rev Microbiol 31, 473-505.

Anderson, P. \& Roth, J. (1981). Spontaneous tandem genetic duplications in Salmonella typhimurium arise by unequal recombination between rRNA (rrn) cistrons. Proc Natl Acad Sci US A 78, 3113-3117.

Baulard, A., Gurdyal, S., Brennan, B. \& Brennan, P. J. (1999). The cell-wall core of Mycobacterium: structure, biogenesis and genetics. In Mycobacteria. Molecular Biology and Virulence, pp. 240-259. Edited by C. Ratledge \& J. Dale. London: Blackwell Science.

Besra, G. S., Morehouse, C. B., Rittner, C. M., Waechter, C. J. \& Brennan, P. J. (1997). Biosynthesis of mycobacterial lipoarabinomannan. J Biol Chem 272, 18460-18466.

Bhatt, K., Banerjee, S. K. \& Chakraborty, P. K. (2000). Evidence that phosphate specific transporter is amplified in a fluoroquinolone resistant Mycobacterium smegmatis. Eur J Biochem 267, 4028-4032.

Brosch, R., Gordon, S. V., Buchrieser, C., Pym, A. S., Garnier, T. \& Cole, S. T. (2000). Comparative genomics uncovers large tandem chromosomal duplications in Mycobacterium bovis BCG Pasteur. Yeast 17, 111-123.

Cole, S. T., Brosch, R., Parkhill, J. \& 38 other authors (1998). Deciphering the biology of Mycobacterium tuberculosis from the complete genome sequence. Nature 393, 537-544.

De Bruyn, J., Johannes, A., Weckx, M. \& Beumer-Jochmans, M. P. (1981a). Partial purification and characterization of an alcohol dehydrogenase of Mycobacterium tuberculosis var. bovis (BCG). J Gen Microbiol 124, 359-363.
De Bruyn, J., Weckx, M. \& Beumer-Jochmans, M. P. (1981b). Effect of zinc deficiency on Mycobacterium tuberculosis var. bovis (BCG). J Gen Microbiol 124, 353-357.

Dye, C., Scheele, S., Dolin, P., Pathania, V. \& Raviglione, M. C. (1999). Consensus statement. Global burden of tuberculosis: estimated incidence, prevalence, and mortality by country. WHO global surveillance and monitoring project. J Am Med Assoc 282, 677-686.

Edlund, T. \& Normark, S. (1981). Recombination between short DNA homologies causes tandem duplication. Nature 292, 269-271.

Evans, M. \& Dyson, P. (1993). Pulsed-field gel electrophoresis of Streptomyces lividans DNA. Trends Genet 9, 72.

Galamba, A., Soetaert, K., Buyssens, P., Monnaie, D., Jacobs, P. \& Content, J. (2001). Molecular and biochemical characterisation of Mycobacterium smegmatis alcohol dehydrogenase C. FEMS Microbiol Lett 196, 51-56.

Haack, K. R. \& Roth, J. R. (1995). Recombination between chromosomal IS200 elements supports frequent duplication formation in Salmonella typhimurium. Genetics 141, 1245-1252.

Hauser, P. M. \& Karamata, D. (1994). Characterization of the chromosomes of Bacillus subtilis merodiploid strains by quantitative DNA-DNA hybridization. Microbiology 140, 1605-1611.

Heath, J. D. (1992). Control of chromosomal rearrangements in Escherichia coli. PhD thesis, University of Texas, Health Science Center.

Hinds, J., Mahenthiralingam, E., Kempsell, K. E., Duncan, K., Stokes, R. W., Parish, T. \& Stoker, N. G. (1999). Enhanced gene replacement in mycobacteria. Microbiology 145, 519-527.

Laemmli, U. K. (1970). Cleavage of structural proteins during the assembly of the head bacteriophage T4. Nature 227, 680-685.

Lee, R. E., Brennan, P. J. \& Besra, G. S. (1996). Mycobacterium tuberculosis cell envelope. Curr Top Microbiol Immunol 215, $1-27$.

Levy-Frebault, V. V., Thorel, M. F., Varnerot, A. \& Gicquel, B. (1989). DNA polymorphism in Mycobacterium paratuberculosis, 'wood pigeon mycobacteria', and related mycobacteria analyzed by field inversion gel electrophoresis. J Clin Microbiol 27, 2823-2826.

Lupski, J. R., Roth, J. R. \& Weinstock, G. M. (1996). Chromosomal duplications in bacteria, fruit flies, and humans. Am J Hum Genet 58, 21-27.

McFadden, J. (1996). Recombination in mycobacteria. Mol Microbiol 21, 205-211.

Menard, R., Sansonetti, P. J. \& Parsot, C. (1993). Nonpolar mutagenesis of the ipa genes defines IpaB, IpaC, and IpaD as effectors of Shigella flexneri entry into epithelial cells. J Bacteriol 175, 5899-5906.

Merkel, J., Feldblyum, T., Young, B., Kriakov, J., Jacobs, W. R., Jr \& Fleishmann, R. D. (2001). Sequencing and assembly of the Mycobacterium smegmatis genome. In Keystone Symposium B1: Molecular and Cellular Aspects of Tuberculosis Research in the Post Genome Era, p. 62. Edited by G. Kaplan, S. T. Cole \& B. Brennan. Taos, New Mexico.

Mikusova, K., Mikus, M., Besra, G. S., Hancock, I. \& Brennan, P. J. (1996). Biosynthesis of the linkage region of the mycobacterial cell wall. J Biol Chem 271, 7820-7828.

Papavinasasundaram, K. G., Colston, M. J. \& Davis, E. O. (1998). Construction and complementation of a recA deletion mutant of Mycobacterium smegmatis reveals that the intein in Mycobacterium tuberculosis recA does not affect RecA function. Mol Microbiol 30, 525-534. 
Parish, T. \& Stoker, N. G. (2000). Use of a flexible cassette method to generate a double unmarked Mycobacterium tuberculosis tly A plcABC mutant by gene replacement. Microbiology 146, 1969-1975.

Parish, T., Gordhan, B. G., McAdam, R. A., Duncan, K., Mizrahi, V. \& Stoker, N. G. (1999). Production of mutants in amino acid biosynthesis genes of Mycobacterium tuberculosis by homologous recombination. Microbiology 145, 3497-3503.

Pavelka, M. S., Jr \& Jacobs, W. R., Jr (1999). Comparison of the construction of unmarked deletion mutations in Mycobacterium smegmatis, Mycobacterium bovis bacillus Calmette-Guerin, and Mycobacterium tuberculosis $\mathrm{H} 37 \mathrm{Rv}$ by allelic exchange. J Bacteriol 181, 4780-4789.

Pelicic, V., Reyrat, J. M. \& Gicquel, B. (1996a). Expression of the Bacillus subtilis sacB gene confers sucrose sensitivity on mycobacteria. J Bacteriol 178, 1197-1199.

Pelicic, V., Reyrat, J. M. \& Gicquel, B. (1996b). Generation of unmarked directed mutations in mycobacteria using sucrose counter-selectable suicide vectors. Mol Microbiol 20, 919-925.

Philipp, W. J., Poulet, S., Eiglmeier, K. \& 7 other authors (1996). An integrated map of the genome of the tubercle bacillus, Mycobacterium tuberculosis $\mathrm{H} 37 \mathrm{Rv}$, and comparison with Mycobacterium leprae. Proc Natl Acad Sci US A 93, 3132-3137.
Ray, T., Weaden, J. \& Dyson, P. (1992). Tris-dependent sitespecific cleavage of Streptomyces lividans DNA. FEMS Microbiol Lett 96, 247-252.

Sambrook, J., Fritsch, E. F. \& Maniatis, T. (1989). Molecular Cloning: a Laboratory Manual, 2nd edn. Cold Spring Harbor, NY : Cold Spring Harbor Laboratory.

Spector, T. (1978). Refinement of the Coomassie blue method of protein quantitation. A simple and linear spectrophotometric assay for less than or equal to $0 \cdot 5$ to $5 \cdot 0$ microgram of protein. Anal Biochem 86, 142-146.

Stelandre, M., Bosseloir, Y., De Bruyn, J., Maes, P. \& Content, J. (1992). Cloning and sequence analysis of the gene encoding an NADP-dependent alcohol dehydrogenase in Mycobacterium bovis BCG. Gene 121, 79-86.

Tekaia, F., Gordon, S. V., Garnier, T., Brosch, R., Barrell, B. G. \& Cole, S. T. (1999). Analysis of the proteome of Mycobacterium tuberculosis in silico. Tuber Lung Dis 79, 329-342.

Wilkin, J. M., Soetaert, K., Stelandre, M. \& 7 other authors (1999). Overexpression, purification and characterization of $\mathrm{MycO}-$ bacterium bovis BCG alcohol dehydrogenase. Eur J Biochem 262, 299-307.

Received 15 June 2001; revised 30 July 2001; accepted 14 August 2001. 